\title{
Impact of Using Technology in Auditing on Reducing the Fees of Auditors Offices and Companies in Jordan
}

\author{
Ali Mustafa Magablih ${ }^{1}$ \\ ${ }^{1}$ Irbid national university, Jordan \\ Correspondence: Ali Mustafa Magablih, Irbid national university, Jordan. E-mail: Alimagablih@yahoo.com
}

Received: April 25, 2019

Accepted: May 30, 2019

Online Published: July 7, 2019

doi:10.5539/ijbm.v14n8p1

URL: https://doi.org/10.5539/ijbm.v14n8p1

\begin{abstract}
The current study aimed to identify the impact of using technology in auditing on reducing the fees of the auditors offices and companies operating in Jordan. To achieve this objective, the study adopted the descriptive analytical approach due to its suitability to the nature of the study. A questionnaire was adopted as the study tool where 280 questionnaires were distributed to the study sample, 216 were retrieved and 184 were analyzed after excluding 32 questionnaires since they were invalid for the statistical analysis. The researcher used some appropriate statistical methods such as $\mathrm{T}$ test, mean and standard deviation. The study had many results, most important of which are that using technology has an impact on reducing the audit fees for the auditor offices and companies due to its accuracy in data output and tabulation, and that the auditor practices the E-auditing efficiently since he realizes its various benefits for the audit offices and companies operating in Jordan, and they applied it to a high degree. The study recommended the need for the audit offices and companies to continue operating in Jordan through e-auditing and they should work on developing their methods of application.
\end{abstract}

Keywords: impact, technology, auditing, reducing, fee, auditors offices and companies

\section{Introduction}

The recent years have witnessed dramatic developments in the information and communication technologies, computers, software and applications; IT entry into the world of money and business has also caused significant changes in information systems in terms of preparing, analyzing and presenting data and information. With the increased technical development, it was necessary to prepare data to increase the speed and accuracy of achievement and reduce the cost of preparing it. Reliance on the IT has become significant among the various types and sizes of economic organizations, which led to opening new areas in the world of accounting where its impacts have appeared on the audit process. Furthermore, there is a need to have an auditor who is capable of auditing information in light of the information technologies and the electronic operating environment, and also the need for methods and procedures of auditing that are different from special methods and procedures under the traditional auditing of manual systems.

During auditing in the information technology and electronic data-processing environment, the auditor faces many factors leading him towards using the applications of those technologies, including using the electronic calculator in auditing. Using such techniques has been reflected in the scope of the responsibility of the auditor to meet the requirements for the beneficiaries as a result of conducting the audit procedures in the information technology environment while preparing the required data.

Using information technology has impacted the financial and accounting activities and the internal controls in business processes, where the audit process using the information technology helps improve the efficiency and effectiveness of external audit and achieve it in less time which would contribute in improving the quality of auditing and increasing the profit of audit offices and companies and their market share.

Jordan, like other countries in the world, is affected by the technological development; most audit offices and companies use computer technology to conduct auditing; therefore, we examine the impact of using technology on reducing fees in terms of several dimensions such as working time, audit costs and the authenticity of electronic documents as a proof.

\subsection{Problem}

Lack of keeping pace with the development in the era of information technologies and their use led to 
determining the auditor's responsibility within the sample size that has been tested and enhancing the confidence among beneficiary regarding the auditor's report which would leave the profession unable to keep abreast of the renewal in the world of IT revolution which is characterized by a growing speed in many fields in addition to the beneficiaries' needs of data on the activity results and the progress of business. Using information technologies in view of their potential and advantages has eliminated the justifications used under the previous conventional method through using samples test due to problems in time, effort and costs, large size of business, auditor's limited responsibility in light of the sample being tested and lack of possibility of presenting new, professional services such as confirmation services and trust to keep up with the needs of beneficiary; this disables the profession to meet the requirements of the beneficiary parties.

The audit offices and companies in Jordan rely on technology in auditing; the question is: what is the impact of using technology in auditing on reducing audit fees? Therefore, the study problem lies in answering the following key questions:

1- What is the impact of using technology for auditing on reducing the audit fees of audit offices and companies in Jordan?

The above mentioned main question consists of the following sub-questions:

A. What is the impact of using technology on reducing the time required for auditing in the audit offices and companies in Jordan?

B. What is the impact of using technology on reducing the costs required to complete the audit process in Jordan's audit offices and companies?

C. What is the impact of using technology on obtaining electronic documents such as a reasonable confirmation evidence that data are free from the physical deviations in Jordan's audit offices and companies?

\subsection{Importance}

The importance of the research lies in the need for clarifying the developments in the profession and the services required by the beneficiaries which are provided by information technologies, whose use requires the availability of scientific and practical qualifications of the auditor and the implications for the scope of the legal, professional and ethical responsibilities for developing the process of auditing and fulfilling obligations to keep up with the renewed developments in the information technology environment and what it imposes on the auditing profession. The research also attempts to deepen the electronic knowledge, services of confirmation, trust, electronic publishing and using the method of consistent auditing as well as the modern programs and applications in the audit process and identify the impact of those techniques on the auditor's responsibility.

\subsection{Objective}

The research aims to identify the extent to which auditors in Jordan are committed to the subject of modern techniques in the process of auditing and the legal, professional and social ethical responsibilities which are connected to the profession in light of the modern technologies and their contemporary crises and threats. The research also aims to identify the modern trends of the auditing profession and the global and professional publications and their impact with the modern techniques through:

1-identifying the extent of using electronic auditing devices and software in the audit offices and companies operating in Jordan.

2. Analyzing the impact of using the electronic audit methods on the audit fees for the audit offices and companies in Jordan.

\subsection{Hypotheses}

Information technologies have implications that are reflected on the responsibility of the auditor; using such techniques that include hardware, software and applications will result in several advantages such as speed and accuracy in the audit procedures which results in the disappearance of justifications for adopting the statistical sampling in making test which leads to expanding the auditor's responsibility. Accordingly, the following hypotheses emerge:

\subsubsection{Main Hypothesis}

There is no statistically significant impact for using technology in auditing on reducing the fees of audit offices and companies in Jordan.

The main hypothesis has the following sub-hypotheses: 
A. There is no statistically significant impact for using technology on reducing the time required for auditing in the audit offices and companies in Jordan.

B. There is no statistically significant impact for using technology on reducing the costs required to complete the audit process in the audit offices and companies in Jordan.

C. There is no statistically significant impact for using technology on obtaining electronic documents such as reasonable confirmation documents on the fact that the data are free of physical deviations in the audit offices and companies in Jordan.

\subsection{Methodology}

The researcher adopted the following two approaches:

1-the descriptive approach in identifying the theoretical framework by using periodicals, books, laws, regulations, official bulletins and international auditing standards.

2. The deductive approach through promoting the theoretical results via questionnaires.

\subsection{Means of Data Collection}

For data collection, the researcher adopted the following:

A. In preparing the theoretical aspect, the researcher adopted a number of Arab and international references represented in books, periodicals, laws, documents, as well as the Internet.

B. In preparing for the field work, the researcher adopted the questionnaire to obtain the information required for the completion of the research. The questionnaire consisted of three aspects: first: definitions used in the study, second: general information on the research auditors and third: questions addressed to auditors (research sample) through which fifth Likert scale was used.

\section{Previous Studies}

(Momani, 2007), entitled with "factors and constraints affecting using information technology in auditing from the perspective of auditors in Jordan", aimed to identify the extent of using technology in the audit offices by exploring the viewpoint of auditors in Jordan, as well as the impediments to their use in such offices; the study concluded that the audit offices, the sample, intends to use the information technology in its work in case there are conditions that ensure their safe use; however, such offices are aware of the importance and benefits of using the information technology in their operations, but using it in a specialized field such as auditing has not reached the required competitive level. The results also concluded that the most important obstacles of using technology in these offices are represented in the lack of public programs that can be used by auditors in their offices, as well as the lack of the auditors' familiarity with the method of using information technology in auditing.

6-(Hamdouna and Hamdan, 2008), entitled with "the extent of using information technology in the audit process-electronic audit-in Palestine and its impact on obtaining a high-quality evidence to support the impartial technical opinion of the auditor on the fairness of the financial statements", aimed to measure the extent of using the electronic auditing in the auditing processes of planning, control and documentation by the audit offices in Palestine, as well as measure the main obstacles and problems related to this. The critical aspect of this study was represented in figuring out the impact of the electronic audit on the quality of evidence which is the focus of the auditing process. The study resulted that the auditors in Palestine use the electronic audit in various audit activities below average in planning, control and documentation. As for the overall impact of using the information technology in the audit process (electronic auditing) on improving the quality of evidence, it was referred to as medium; furthermore, there were many variables affecting the quality of audit evidence regardless of the information technology.

7- (Hassoun, 2009), entitled with "internal control system in light of the electronic operation of accounting data and the performance of the auditor-applied research in the South Oil Company" is an applied study conducted in Iraq and it aimed at identifying the skills required to be in auditors for performing their jobs in auditing the electronic accounting systems, proposing solutions that enhance confidence in the internal control system, identifying the characteristics of the customer's electronic operating environment and the risks that threaten the security of these systems, knowing the causes of such risks and providing protection procedures to them, and identifying the challenges faced when evaluating the internal control system in the electronic operating environment. The study concluded that there was an expansion of the concept of the professional competence through using electronic systems to include qualifications and capabilities that did not exist under the manual operation in addition to the expansion of the concept of the evidentiary standards in order to include novel evidence. The study recommended the need for providing electronic audit programs, training the employees of 
the Financial Supervision Bureau and the professors of the Arab Institute of Chartered Accountants in order to identify the audit methods and procedures via computers, the need for paying attention to the development programs in the electronic auditing by the Association of Accountants and auditors and finally the need for adding an item on auditing via computers by the Board of the Audit as a requirement to pass the audit control test by professionals.

7-(Al-Jumaily, 2010), entitled with "Using computer-assisted audit method in auditing the electronic operation of data approved in the Financial Control Office", is an empirical study in Iraq that aimed to identify the motives leading the auditor to use computer techniques in audit, the benefits of using computers in conducting audit procedures, requirements that must be met in the auditor, and the methods used in the electronic operation of data under its global applications in its stages and procedures as well as the attempts of developing the performance of the Office of Financial Control through using computer-aided audit tools via IDEA. The study concluded that the rate of auditors in the financial control office who performed auditing via computers was low. The study recommended the need to pay attention to the scientific and practical qualification of the bureau employees through using methods and procedures of auditing the electronic operating systems and computer technologies, as well as the need for forming electronic audit teams within each audit department heading towards a computer-aided audit method.

9-(Al-Bawi, 2010),entitled with "the impact of electronic audit on the efficiency and effectiveness of audit procedures-an empirical study on a sample of auditors in Amman/Jordan", is an empirical study that aimed at highlighting the electronic audit methods applied by the audit offices in Jordan in accordance with the international auditing standards and data and identifying the advantages and disadvantages of using e-auditing programs and measurement of the impact of the independent variable (electronic audit) on the dependent variable (efficiency and effectiveness of audit procedures). The study concluded that the auditors in Jordan use information technologies in various activities related to audit, documentation and registration of control operations and procedures. Using information technologies by auditors also contributes significantly to improving the efficiency and effectiveness of auditing, both in terms of reducing time, number of users in audit offices, and the costs of the audit process, increasing the job satisfaction of the owners of the office and increasing their fame and increasing the access to new customers. Auditors are also aware of the importance of using information technologies in auditing accounts. The audit of accounts in the Jordanian companies takes important steps and needs to strengthen the belief of using such technologies and moving into the automated auditing.

\subsection{Theoretical Framework}

The automation of the electronic audit in the framework of data technology is important for keeping abreast of the significant development of the modern software and techniques, which resulted in different audit methods in auditing risks and using the tools and procedures of specialized information IT programs by completing the e-audit process.

\subsubsection{Auditing and Information Technology}

There have been various uses on many modern platforms, in their use of technology to carry out their business and process their data; they help build successful institutions and companies, help them build good relationships with their customers, increase their market share, and help in the process of making decisions, improving productivity, and encouraging competition since auditors can use computer programs that can dialog client programs. This process is helpful in conducting auditing in a fast and accurate method.

\subsubsection{Audit Procedures and Manuals under Electronic Audit}

There is a distinct difference between the audit procedures used by the external auditor in the manual auditing process and those used when applying the electronic audit technology for the following reasons:

-There is no documentary evidence, which can be read to verify the implementation of some control procedures used in the electronic audit, which requires the auditor to use different methods to make certain tests.

-The files and records used in the electronic audit are most often written via computers.

-An important and key feature in the processing of electronic data is that it is characterized by its large size and accuracy which results in lower rate of negligence errors, lack of concentration, or fatigue.

\subsubsection{Evidence}

In terms of auditing, the guide is defined as information used to identify the extent of compatibility between the financial information and the predetermined criteria; here, the auditor must get sufficient, appropriate and 
credible evidence, so that he can make logical conclusions in order to be the basis on which he can build his professional viewpoint; the auditor may not have any paper records when using IT; therefore, the auditor should take into account the impact of information technology when trying to get evidence to ensure the integrity of operations. There is no doubt that through using IT, most records become unphysical as the case with the manual mode; they can be easily destroyed, disposed of, or modified without any trace or proof of vandalism or modification.

\subsubsection{Role and impact of Information Technologies on Expanding the Responsibility of Auditors}

In recent years, there have been significant scientific developments in many areas, especially with regards to information technologies that have become increasingly frequent and they started to affect various areas of life, including accounting and auditing. With this new form found in a technology-based operating environment, professionals concerned with these developments, including auditors and audit offices, have a large burden, as they have to adapt to new operating techniques; they must understand the physical components of the computer and its peripherals, software as well as the electronic operating systems, applications, networks, as well as the special skills and capabilities they have to possess to be able to plan the audit tasks and understand the implications of using and processing the information technology systems for all forms of audits as they affect the audit process and the judgement adopted by the auditor from the audit outputs representing his report on businesses. Auditors are mainly concerned with the impact of these techniques used in the internal control systems as a first step of his work and on which they are relied in terms of planning auditing and their impact on the procedures of auditing that will be applied in the work of the test of these operations and their results.

\subsection{Information Technologies and Their Impact on Expanding the Auditor's Responsibilities}

\subsubsection{Introduction to Information Technologies}

Information technologies have become one of the most important means used by various types of businesses either profitable or non-profitable in their various operations either in planning, supervision, documentation, or administrative, accounting or other aspects of activities. At the same time, auditing has witnessed a growing development in keeping abreast of developments in the information technologies of these enterprises; as a result of this, the so-called computerized systems audit or computer audit appeared; the traditional methods no longer fit the audit process in light of the electronic processing of data. The accounting systems provide information in large sizes, high speed and greater degree of accuracy and efficiency more than before. This field witnessed continuous developments and it has increasing attention along with the professional standards were issued which would guide auditors in this area. Computers were used to perform new services in this field; the problems facing the auditors via traditional methods in big enterprises made auditing difficult, arduous and costly at the same time; however, with the start of using audit computers, systems and programs, the standards changed so that they allowed auditors to make a comprehensive and accurate control over the accounts, which facilitated their work. Information technologies provide the computer hardware and networks required for auditing, and they help get auditors who are able to keep abreast of these technologies in using computers as a tool for auditing, using automated systems, understanding the automated systems, the purpose of these systems, and the environment in which systems work.

\subsubsection{Nature of the Information Technology Environment}

It has been stated that there is no specific definition for the term information technology scientifically or practically at the global, Arab or local levels because of the multiple environments and businesses created by the information technologies. Despite the fact that the IT at its stages depend on the computer, some consider it as using computer techniques; however, the auditing profession finds itself in a situation where it is necessary to reconcile or adapt to this challenge, which has imposed itself more forcefully than before; IT depends on the information technology environment in all stages.

IT has passed through different developments in terms of the way of operation from a manual to an automated method and from using the electronic calculator to the techniques of using satellites. This rapid development has helped the development of computer technologies.

The scope of computer information technologies has also expanded to be included in all fields and activities and they are useful in using concepts and methods of scientific research and management such as:

-Industrial intelligence

-experience systems

-comprehensive quality management systems 
-self-control systems

-Integrated database systems

-Information feedback systems

Furthermore, there are many risks in the information technology environment, which can be categorized and divided into:

1. Operating risks (inadequate system insurance, inadequate systems design, poor maintenance, and misuse).

2. Reputational risks (effective penetration).

3. Legal risks (anti-money laundering, violation of conventions and lack of clear definition of rights and obligations).

4. Other risks (traditional risks and market risks).

Information technologies have evolved and expanded as a result of the development of the computer systems and their spread in all the fields of life. Such spread made most businesses mainly rely on those systems. This was not limited to operating data but it also expanded to using such systems in transmitting, using and sending data to its users along with the spread of the trade systems, electronic exchange systems, electronic Gov. Services' systems and the electronic business systems and e-commerce.

Next emerged the need for a special audit in the information technology environment, which has been supported by scientific and professional societies and assemblies at the global level, the latest of which is the International Federation of Accountants (IFAC) through the International Auditing and Assurance Standards Board (IAS), where the international audit standard (No. 400) in item (33) indicated in the information system environment where computers are used, the objectives of the control tests do not change from those in the manual environment, yet some audit procedures may change, and the auditor may find himself obliged or he may prefer to use computer-aided audit methods. The international audit standard (401) in item (12) stated that "the audit objectives do not change in the case of processing the accounting information manually or electronically. However, the methods of applying audit procedures to collect evidence may be affected by the methods of computer processors, and the auditor can use manual procedures to audit or use the electronic audit or both methods.

\subsubsection{Importance of Information Technologies}

The development in the technical aspects, the rapid development in businesses and coping up with change is one of the most important economic factors that work to increase production; the society which do not seek to keep up with the scientific and technical development soon finds itself incapable of entering the new era and make appropriate recommendations. Information technology is one of the scientific fields that seek to use advanced systems and methods in various aspects of life to ensure the best performance by employing these techniques in the preparation of programs and applications to practice greater levels of business.

Researchers and strategists have predicted the information revolution; such predictions of life became a reality in the recent years, and now we are living in the age of information, an era which has the ability to generate new knowledge that has become the main engine of the social and economic growth; this era is also characterized with computers everywhere, global communication networks, electronic publishing and digital libraries and the information age has become a reality since it entails unprecedented job opportunities for information professionals who know how to organize and use informational assets and who possess analytical skills and the proper technicality to identify the information strategy for all types of organizations.

The field facts indicate that the information technology has contributed in:

1 - Improving production in $51 \%$ of US companies.

2- Reducing costs by $39 \%$.

3- Improving decision making by $36 \%$.

4- Strengthening customer relationships by $33 \%$.

5- Developing the use of a new strategy by $33 \%$.

2.3 Information Technologies and Their Impact on Extending the Responsibility of Auditors

After the development in the business environment, the international economic openness and the impact of globalization on the economies of countries, the perception towards auditing changed. This required from the auditor providing services in line with the developments more than the traditional tasks in order to achieve the 
modern tasks that suits the technical progress in the open business environment. The traditional auditing functions are limited to verifying the validity of the accounting data and expressing a neutral technical opinion on such data. Such objectives expanded to reach other objectives that are derived from these basic objectives.

The dominant feature of many modern organizations has become the use of IT in conducting their business and processing their data; it helps build successful organizations, build distinguished relationships with their customers, increase their market share and improve productivity. Such developments in IT subjected the auditing profession to a large challenge to develop its tools and methods to continue providing its services with a high quality. Therefore, the so-called electronic audit or computerized systems audit appeared; such technologies will help the auditing profession to overcome some aspects of human deficiency in the case of practicing the appropriate professional governance and expressing opinions. In light of the developed environment of information technology, auditors face significant challenges so they should understand the different characteristics of that environment. There are a number of common characteristics that can be added to the environment of information technologies including:

1. Concentration of data and office records in the Computer Management.

2. Difficulties in tracking processes.

The auditor's responsibility with respect to the audit services is limited to expressing an opinion on the soundness of the financial statements, the fairness of representing the financial position and the business outcome, and expressing an opinion on the validity of the financial data. The auditor is also entitled to obtain the sufficient evidence to be able to judge the authenticity of the accounting data and representing the different operations and activities of the organization especially if the data and records of the financial statements are electronically set. Generally speaking, the steps and procedures of auditing the information technologies are influenced by the nature of the audit elements which correspond to the nature of the electronic operation of processes and operations in addition to the auditing method on the other hand.

The information technologies focused on control through combining the IT and the accounting systems by:

1. Replacing the manual control with the computerized control.

2. Providing information technology systems for data of a high quality.

3. Relying on the functional capabilities of the computer hardware and software with no physical protection.

4. Interrupting the audit stream.

5. Little participation of individuals.

6. Systemic errors regarding random errors.

7. Unauthorized access.

8. Reducing tasks' segregation.

9. Data loss.

\section{Study Population and Sample}

The study population consists of 424 certified auditors in Jordan; a random sample of 280 professional auditors has been withdrawn; 216 questionnaires were retrieved and 32 questionnaires were excluded that the total number of appropriate questionnaires was 184. Questionnaires were then collected; afterwards, the researcher used the SPSS to analyze answers and conclude results.

\subsection{Statistical Methods used in the Study}

-frequencies and percentages: to identify the characteristics of the study sample.

-mean: To see how high or low the respondents' answers to each item were.

-Standard deviation: to determine the dispersion of respondents ' answers to the study means.

- (One Sample T test) for one sample.

\section{Testing the Study Hypotheses}

\subsection{Testing the Main Hypothesis}

There is no statistically significant impact for using technology in auditing on reducing the fees of audit offices and companies in Jordan at sig. $(\leq 0.05)$.

To test this hypothesis, T-test for one sample was used to measure the impact of using technology in auditing on 
reducing the fees of audit offices and companies in Jordan at sig. $a \leq 0.05$; the mean of all items was 4.03 , the calculated T was 21.467, which is greater than the value of IT, which equals 2 and the level of significance was $(0.000)$ which is less than $\mathrm{a} \leq 0.05$; accordingly, the null hypothesis is rejected and the alternative hypothesis is approved.

There is a statistically significant impact for using technology in auditing on reducing the fees of the audit offices and companies in Jordan at sig. $(\leq 0.05)$.

As for testing the sub-hypotheses emanating from this hypothesis, it was found that

\subsection{Testing the First Sub-Hypothesis}

There is no statistically significant impact for using technology on reducing the time required to audit in the audit offices and companies in Jordan at sig. $(\leq 0.05)$.

The result of the test shows that the mean of all items was 3.96, the calculated value of $\mathrm{T}$ was 21.428 , which is greater than the value of $T$, which equals 2 , the level of significance was $(0.000)$ which is less than $a \leq 0.05$. Accordingly, the null hypothesis is rejected and the alternative hypothesis stating that there is a statistically significant impact for using technology on reducing the time required for auditing in the audit offices and companies in Jordan at sig. $(\mathrm{a} \leq 0.05)$ is approved.

\subsection{Testing the Second Sub-Hypothesis}

There is no statistically significant impact for using technology on reducing the costs required to complete the auditing process in the audit offices and companies in Jordan at sig. $(\leq 0.05)$.

The test result shows that the mean of all the items was 3.92, the calculated value of $\mathrm{T}$ was 16.687 , which is greater than the value of $\mathrm{T}$, which equals 2 , the level of significance was $(0.000)$, which is less than $\mathrm{a} \leq 0.05$; accordingly, the null- hypothesis is rejected and the alternative hypothesis stating that there is a statistically significant impact for using technology on reducing the costs required to audit in the audit offices and companies in Jordan at sig. $(\mathrm{a} \leq 0.05)$ is approved.

\subsection{Testing the Third Sub-Hypothesis}

There is no statistically significant impact for using the technology to obtain electronic documents as evidence for the data's lack of errors in the audit offices and companies in Jordan at sig. $(\leq 0.05)$.

The test result shows that the mean of all items was 3.9, the value of $\mathrm{T}$ was 18.551 , which is greater than the value of $T$, which equals 2 and the level of significance was $(0.000)$ which is less than $a \leq 0.05$. Therefore, the null hypothesis was rejected and the alternative hypothesis which states that there is a statistically significant impact for using technology in obtaining electronic documents as evidence for the data's lack of deviations in the audit offices and companies in Jordan at sig. $\mathrm{a} \leq 0.05$ was approved.

\section{Conclusions and Recommendations}

\subsection{Conclusions}

Based on the theoretical framework of the study, the results of the statistical analysis, and the hypothesis test, the study concluded various points that can be summarized in:

-Using technology in the audit process has an impact of lowering the fees of audit offices and companies in Jordan; auditors conduct the electronic auditing since they are aware of the fact that the electronic auditing has many advantages through which they can reduce the audit fees and thus compete in the market.

-Using the electronic audit leads to less audit time, less effort and more ability to expand the sample size; this increases the auditor's trust in his neutral technical opinion in the financial statements.

-The results showed that the audit offices and companies operating in Jordan are applying the electronic audit; the auditor's knowledge in the e-auditing is a basic means of success in practicing the profession

-the results of the study showed that the authenticity of the electronic documents as evidence was ranked first in terms of being affected by the electronic audit.

\section{Recommendations}

According to the results reached in the theoretical framework of the study and the reality of the statistical analysis of data, the study recommends the following:

-The audit offices and companies in Jordan still apply the electronic audit and they work on solving the problems and difficulties that impede the application of electronic audit by increasing the efficiency of the scientific and 
practical mechanisms of auditors.

-The need that the related agencies hold seminars and lectures to educate the audit offices and companies in Jordan regarding applying the electronic audit due to its impacts on the lists of companies and the transparency of their information.

-Working on applying the electronic auditing since it enables auditors to verify the validity and accuracy of data processing and shortens the time of the audit process.

\section{References}

Adeyemi et al. (2014). Audit Technology Tools and Business Process Assurance: Assessment of Auditors' Perspective in management Nigeria. Universal Journal of Industrial and Business Management.

Al-Jabari, T. (2004). The Impact of Information Technology on the Internal Audit Process in Jordan. Master Degree, Amman Arab University for Graduate Studies, Faculty of Managerial and Financial Graduate Studies, Amman, Jordan.

American Institute Of Certified Public Accountants (AICPA). (2014). The Auditors Consideration Of The Internal Audit Function in an Audit Of Financial Statements. Statements on Auditing Standards NO.65, New York.

Arens \& Randal J. Elder \& Mark S. Beasley. (2014). Auditing and Assurance Services an Integrated approach (9th ed). Prentice Hall, USA.

Elizabeth, C., \& Carling , D. (2012). The Competitive Advantage of Audit Support System. The Relationship Between Extent of Structure and Audit Pricing. Journal of Information System.

Hanini, F. (2012). The role of using information technology to improve the quality of audit services Jordan. A field study on auditing companies and offices operating in Jordan.

IAASB. (2014). A Framework for Audit Quality: Key Elements that Create an Environment for Audit Quality. International Federation of Accountants (IFAC).

Khalidi, N. (2013). The impact of the use of electronic data-processing methods has increased effectiveness Audit offices operating in the Gaza Strip.

Omoneye, O. O. (2013). Computer Aided Audit Techniques and Fraud Detection.

Shanti, A. (2013). The impact of the application of accounting information systems on improving effectiveness and efficiency Internal Audit in the Jordanian Industrial Sector.

Thunibat, A. A. (2010). Audits in light of international standards, regulations and laws Local, theory and application. Third Edition, Amman, Jordan.

\section{Copyrights}

Copyright for this article is retained by the author(s), with first publication rights granted to the journal.

This is an open-access article distributed under the terms and conditions of the Creative Commons Attribution license (http://creativecommons.org/licenses/by/4.0/). 